\title{
Health insurance coverage of genetic services in Illinois
}

\author{
Megan Latchaw, MS, MA ${ }^{1,2}$, Kelly Ormond, MS $S^{1,3}$, Maureen Smith, MS ${ }^{1}$, John Richardson ${ }^{4}$, \\ and Catherine Wicklund, $M S^{I}$
}

\begin{abstract}
Purpose: As a first step toward the improvement of health insurance coverage and reimbursement for genetic services, our study characterizes the current state of health insurance coverage for genetic services in Illinois. Methods: We used a combination of surveys, interviews, and policy review to obtain data from the largest health insurers in Illinois regarding their coverage of genetic services. Results: The health insurance companies in this study vary widely on coverage of and attitudes toward genetic services. Policies were most consistent across insurance companies when there was widespread professional agreement regarding genetic testing, as in the case of cystic fibrosis carrier screening. Other policies, including criteria for $B R C A$ testing, were extremely variable across insurers and did not always reflect accurate medical information. We also found that health insurance companies in Illinois seem unlikely to reimburse for services billed directly by genetic counselors. Conclusions: These findings suggest several strategies for improving billing, reimbursement, and insurance coverage of genetic services, including (1) legislative amendments mandating coverage of genetic counselors' services; (2) creating consistent criteria for genetic testing; (3) increasing genetic professionals' involvement in the development of coverage policies; and (4) educating insurance companies about the value of genetic services. Genet Med 2010:12(8):525-531.
\end{abstract}

Key Words: health insurance, coverage, genetic counseling, genetic services, policy

G enetic professionals face multiple barriers to adequate coverage and reimbursement for their services. As summarized by the Secretary's Advisory Committee on Genetics, Health, and Society and Harrison et al., ${ }^{1,2}$ these barriers include health insurance companies' reliance on Medicare decisionmaking models, scarcity of specific Current Procedural Terminology $\left(\mathrm{CPT}^{\circledR}\right)$ codes, poor reimbursement for preventative nonprocedure-based medical services, and lack of inclusion of genetic counselors as recognized providers by Medicare.These problems with coverage and reimbursement limit access to comprehensive genetic services within the health care system and may lead to poor quality of care if genetic services are provided by practitioners who have better billing and reimbursement mechanisms but no specialized training in genetics. ${ }^{1}$

The first step toward improving access to genetic services is to characterize the current state of health insurance coverage of these services. ${ }^{3}$ To date, there have been few studies of the current policies of insurance companies in regard to coverage of

From the ${ }^{1}$ Northwestern University, Chicago, Illinois; ${ }^{2}$ NorthShore University HealthSystem, Evanston, Illinois; ${ }^{3}$ Stanford University, Stanford, California; and ${ }^{4}$ National Society of Genetic Counselors, Chicago, Illinois.

Catherine Wicklund, MS, Northwestern University, 676 N. St. Clair, Suite 1280, Chicago, IL 60611. E-mail: c-wicklund@northwestern.edu.

Disclosure: The authors declare no conflict of interest.

Submitted for publication January 27, 2010.

Accepted for publication April 19, 2010.

Published online ahead of print June 8, 2010.

DOI: $10.1097 /$ GIM.0b013e3181e3916d genetic services. ${ }^{3-6}$ In 2006-2007, the Illinois Department of Public Health ${ }^{7}$ conducted a needs assessment of genetic services and subsequently developed the Illinois State Genetic Services Plan. One of the objectives identified in the report was to characterize the insurance coverage of genetic services on a local level as a means of describing issues that limit adequate reimbursement. Therefore, this study was designed to evaluate current health insurance plans' coverage of genetic services in Illinois using a two-armed approach: the first arm of the study involved surveying medical directors of the 10 largest health insurance companies in Illinois and the second arm consisted of a review of publicly available policies regarding genetic testing and counseling from all health insurance carriers in Illinois. It is our hope that the data obtained in this study, and the methodology of obtaining these data, can be more broadly generalized to other states.

\section{MATERIALS AND METHODS}

\section{Arm 1: Survey}

\section{Survey Sample}

We compiled a list of private third-party payers from annual reports from the Illinois Department of Insurance. ${ }^{8}$ The Illinois Department of Insurance tracks data for health maintenance organizations (HMOs) and indemnity insurers separately. Enrollment data were only available for HMO plans, so we used total premiums collected in 2006 to rank each company in terms of size. We then selected the 10 largest third-party payers in Illinois by 2006 premiums for our survey sample. This sample included both HMO and indemnity insurers.

\section{Data Collection}

We contacted each company through a variety of methods (phone, email, and US Postal Service) between December 2007 and February 2008. When possible, an individual with the title "Senior Medical Director" was telephoned directly. Company websites, press releases, and industry conference attendance lists were searched to identify the names of medical directors at each company. If the name or phone number of a medical director was not available, we attempted to reach a policy maker through the main switchboard. We also emailed every medical director with an obtainable email address and attached a copy of the survey instrument. In addition, we sent two rounds of mailings (one in December and one in January) to medical directors at each company. These mailings included an introductory letter, a copy of the survey instrument, and a selfaddressed stamped envelope. The introductory letter explained the study and allowed respondents to choose their method of participation: in-person interview, telephone interview, emailed survey, or mailed survey. We also initiated contact with media relations representatives and asked them to forward the survey to an appropriate respondent.

Survey participants were informed that the study was funded by the Illinois Department of Public Health. Respondents were assured that their companies would not be identified by name and were sent an executive summary of the results. 


\section{Survey Measure}

The questionnaire, a six-page survey concerning health insurance coverage of genetic services, was designed as a guide for semistructured interviews and was modified to be mailed as a stand-alone survey. Demographic questions inquired about the position of the respondent at the company, the number of people insured by the company in Illinois and nationally, and the number of different health plans offered. Questions about coverage of genetic services addressed whether genetic services are ever covered and how policy decisions about coverage are made. Several scenarios regarding common indications for receiving genetic services were used to assess coverage of preconception, prenatal, pediatric, and adult genetic services. Medical directors were also queried about differing coverage for genetic services depending on type of health care provider. We focused on this area as it is known that reimbursement for genetic counselors is limited by their lack of recognized provider status. ${ }^{1}$ Finally, several questions addressed $\mathrm{CPT}^{\circledR}$ coding, referrals, and reimbursement rates for different providers of genetic services. Interviews based on the questionnaire lasted approximately 1 hour.

\section{Arm 2: Policy review}

The second arm of the study involved a review and comparison of published coverage policies from third-party payers in Illinois. In December 2007 and January 2008, we searched the websites of the companies identified in Arm 1 (a compiled list of all insurance companies registered with the Illinois Department of Insurance ${ }^{8}$ ) for publicly accessible medical policies relating to genetic services. Indexes of policies were searched for "gene," "genetic," and "genetics" and were also browsed policy by policy to identify all relevant publications. We reviewed these publications on the basis of number of policies, policy subjects, level of detail, and criteria for coverage.

This study was exempted from review by the Institutional Review Boards at Northwestern University and Stanford University.

\section{RESULTS}

\section{Survey response rate}

Of the 10 largest (by premiums collected) third-party payers in Illinois, we received a reply from five $(50 \%)$, two of whom declined to participate. Thus, our sample consists of three responses: one in-person interview (Company A) and two mailed surveys (Companies B and C). Together, the three responding insurance companies provide coverage for approximately 3.5 million residents of Illinois ( $>25 \%$ of the state population) and more than 40 million people nationally. An individual with the title of Senior Medical Director completed each survey.

\section{Survey results}

The three companies differed substantially on their policies and attitudes regarding general coverage of genetic services. The medical director of Company $\mathrm{B}$ indicated that genetic services are covered under all health plans when they are related to the "prevention, diagnosis, or treatment of an illness; the information will affect the course of treatment for the plan member; the care and/or treatment is likely to improve outcome; this improvement is attainable outside the investigational setting; and the services are consistent with the health plan design." The medical director of Company A explained that genetic services are only covered if they directly affect patient management and treatment and not to "satisfy curiosity." Elaborating further, this respondent explained that Company A has a responsibility to employers to keep costs low, and they do not see a large benefit to someone "just knowing" his or her genetic status. The medical director of Company $\mathrm{C}$ reported that genetic services are covered only when certain established criteria have been met and referred to the company website for more detail, which outlined guidelines similar to the conditions enumerated by the medical director of Company $\mathrm{B}$.

The survey included several questions about which types of health care providers (e.g., genetic counselors, genetic nurses, or physicians) can be reimbursed for providing genetic services. The medical director of Company B did not answer these questions. The medical director of Company A reported that only providers recognized by Congress or the state General Assembly will be reimbursed for their services. Genetic counselors are not currently recognized as health care providers under Title 18 of the Social Security Act (1965). ${ }^{9}$ In response to questions about "incident to" billing for genetic counselors, the medical director of Company A explained that if a recognized provider submits a claim for a medically necessary service, the bill would typically be paid. This director indicated that Company A would refer to the Medical Practice Act to determine the guidelines for supervision of genetic counselors under the rules of "incident to" billing. Genetic counselors are not mentioned in the Illinois Medical Practice Act of $1987 .{ }^{10}$ The medical director of Company A also stated that there are no requirements that a recognized provider have specialized training in genetics to provide genetic services. The medical director of Company $\mathrm{C}$ wrote that they do not credential genetic service providers and did not answer any other questions about reimbursement.

When asked what steps genetic counselors would need to take to become recognized providers under policies of Company $\mathrm{A}$, the medical director recommended that genetic counselors follow the example of nurse practitioners by lobbying the Illinois General Assembly to mandate third-party payer direct reimbursement for genetic counselors. This medical director also suggested that if enough large employers requested that genetic counselors be recognized as providers, Company A would consider amending all policies to include coverage of services provided by genetic counselors.

A final series of questions regarding reimbursement for genetic services addressed the specifics of billing for these services. All companies were asked to select from a list the most important factors in determining whether a service will be reimbursed: $\mathrm{CPT}^{\circledast}$ codes, International Classification of Diseases, 9th Revision codes, type of provider, and time spent with patient. Company B indicated that all these factors are important for reimbursement purposes, whereas Company A prioritized the type of provider. The medical director of Company $\mathrm{C}$ did not answer these questions.

The remainder of the survey consisted of scenarios about specific types of genetic services. Questions were related to coverage of these services and whether that coverage varied by provider type. The first scenario described a typical indication for seeking genetic services: a pregnant woman older than 35 years undergoes amniocentesis. All companies would cover the amniocentesis, but only Companies $\mathrm{B}$ and $\mathrm{C}$ would cover the consultation with a genetic counselor. All three companies said that prenatal genetic services are generally covered under their health plans, including genetic carrier screening if the woman is pregnant, although there are some policy limitations for what is covered regarding ethnicity-based carrier screening. Only two companies (B and $\mathrm{C}$ ) stated that they cover preconception genetic services (Scenario 2). Specifically, the director of Company A stated that "this information is not medically necessary for the parents because it has no effect on their own health. 
Furthermore, because the woman is not currently pregnant, there is no guarantee that she would become pregnant in the future."

Medical directors reported that coverage for cancer genetic counseling would be equal for women with either a personal or family history of cancer. Companies $\mathrm{A}$ and $\mathrm{C}$ indicated that these counseling services are only covered if the history is strong enough to warrant $B R C A$ testing. Company A would not cover this consultation if provided by a genetic counselor.

The final hypothetical scenario involved an evaluation of a newborn with Down syndrome by a geneticist and a genetic counselor. All three insurance carriers would cover this evaluation, and a physical examination would only need to be performed for the consultation to be covered if billed using a code for physical examinations. Company B generally covers all pediatric diagnostic genetic services. Evaluations by a geneticist are always covered if indicated under policies of Company A, but diagnostic genetic testing is only covered if the diagnosis cannot be made by any other means and the diagnosis would change medical management for the patient. The medical director of Company $\mathrm{C}$ reported that pediatric diagnostic services are covered "with limitations" but did not define these criteria.

\section{Policy review results}

Ten third-party payers in Illinois had coverage policies publicly available on their websites. Published policies addressed a total of 41 topics, most of which were related to genetic testing for a specific condition (Table 1). Fifteen of the 41 subjects (37\%) were addressed by only one or two companies. The most frequently addressed topics were general genetic testing and $B R C A$ testing. The policy topics can be broadly classified into four categories (Fig. 1): general genetic services (11\%), prenatal services (33\%), pediatric genetic indications (20\%), and adultonset genetic conditions (36\%).

The majority of health insurance companies in Illinois with publicly available policies ( 8 of 10 ) had general guidelines regarding coverage of genetic testing. The five companies that did cover genetic testing had similar criteria under which this testing would be covered: all required that the person be symptomatic or at "direct risk" for the condition, that the results of the genetic test impact management or treatment, and that other testing methods are unavailable or inconclusive. Most policies did not define "direct risk" for inheriting a genetic condition.

Six health insurance carriers in Illinois had policies addressing coverage of genetic counseling services. In almost all policies, coverage of genetic counseling was directly tied to coverage of genetic testing. Two companies identified the health care providers who could be reimbursed for providing genetic counseling; the remaining four companies did not specify provider type for this service. Three companies specifically referenced the 96040 Genetic Counseling CPT ${ }^{\circledR}$ code in the appendix to their policies; one of these three companies explicitly recognized genetic counselors as qualified providers of genetic counseling.

Policies regarding carrier screening for cystic fibrosis (CF) were relatively consistent across insurance carriers. All six companies with a CF screening policy would cover the genetic test for couples seeking prenatal care and couples planning a pregnancy. Four of the six insurers also covered screening for reproductive partners of people affected with $\mathrm{CF}$ and people with a family history of CF.

Policies for coverage of first trimester aneuploidy screening were also very consistent across insurance companies. Four of the five companies with policies on this topic would cover first trimester screening for all pregnant women. The fifth company only covered the screening in women who are not automatically
Table 1 Subjects of genetics-related coverage policies

\begin{tabular}{ll}
\hline Policy subject & Number coverin \\
\hline$B R C A$ testing & 8
\end{tabular}

Genetic testing

Cystic fibrosis carrier screening

Genetic counseling

First trimester screening

Tay-Sachs diagnostic testing

Familial adenomatous polyposis testing

Alzheimer disease

HNPCC testing

Tay-Sachs carrier screening

Gaucher disease carrier screening

Hemoglobinopathy screening

Canavan disease carrier screening

Factor V Leiden thrombophilia

Preimplantation genetic diagnosis

Von Hippel Lindau

Multiple endocrine neoplasia 2

Myotonic dystrophy

Long QT syndrome

Hemochromatosis

Second trimester screening (MSS)

Prenatal diagnosis

Fragile X

Niemann-Pick

Retinoblastoma

Congenital deafness

Huntington disease

Fanconi anemia

Malignant melanoma

Spinal muscular atrophy

mtDNA disorders

Neurofibromatosis

Newborn screening

Hereditary pancreatitis

Primary dystonia

Familial nephrotic syndrome

Charcot-Marie-Tooth 1

CADASIL

Developmental delay evaluation

Ethnicity-based carrier screening panels $0 / 1$

Comparative genomic hybridization microarray $0 / 1$

${ }^{a}$ Service generally covered when specific conditions are met.

${ }^{b}$ Number of companies with a policy on the particular subject (of 10 queried). HNPCC, hereditary nonpolyposis colon cancer syndrome; CADASIL, cerebral autosomal dominant arteriopathy with subcortical infarcts and leucoencephalopathy. 


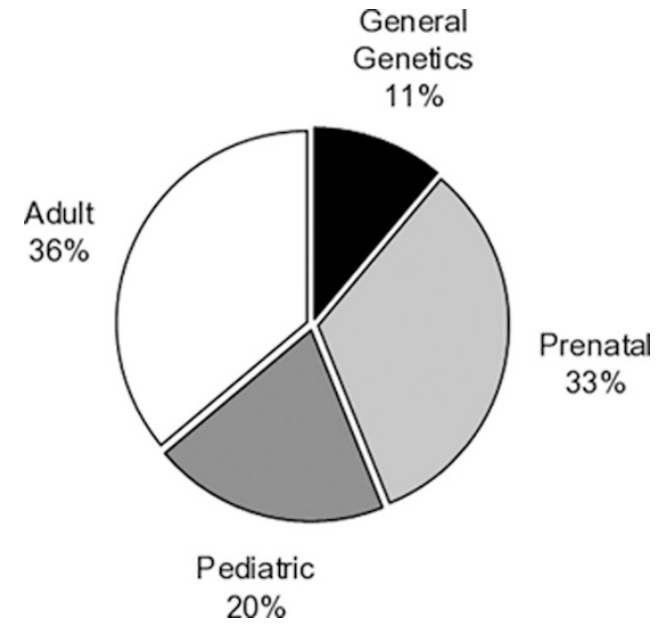

Fig. 1. Distribution of policy topics.

eligible for invasive prenatal testing. "Automatically eligible for invasive prenatal testing" was not defined in this policy.

In contrast to prenatal genetic services, very few health insurance companies provided coverage for genetic testing for Alzheimer disease. None of the five companies with policies regarding testing for Alzheimer disease covered ApoE genotyping, and only one company stated that they cover genetic testing for the genes related to early-onset familial Alzheimer disease.

Coverage policies for genetic testing for hereditary colon cancer syndromes were very consistent across third-party payers. For both familial adenomatous polyposis (FAP) syndrome and hereditary nonpolyposis colon cancer syndrome (Lynch syndrome), almost all companies followed the guidelines described in the Amsterdam II Criteria ${ }^{11}$ and the Revised Bethesda Guidelines ${ }^{12}$ with two minor exceptions. First, one company's policy inaccurately indicated that genetic testing for FAP syndrome is indicated for "individuals who are considered at a high risk for FAP syndrome (high risk is defined as an affected first degree relative); OR to diagnose Klinefelter's syndrome."13 This policy has since been revised. Second, another company had an inherited colon cancer policy that addressed only FAP syndrome and not Lynch syndrome.

Eight of the 10 health insurance companies with published policies had statements regarding genetic testing for hereditary breast and ovarian cancer. The policies addressing coverage of $B R C A$ testing varied widely between insurance carriers in terms of level of detail, specific criteria for coverage, and emphasis placed on the clinician's judgment. In total, third-party payers in Illinois with public coverage policies had 56 separate criteria for coverage of $B R C A$ testing, reflecting the wide variability in coverage for this service. For example, two companies would cover testing in a woman with breast cancer if the ordering provider considers the family history to be suggestive of hereditary breast and ovarian cancer, whereas other policies enumerated the exact number of affected relatives and degree of relatedness needed to qualify for test coverage. In addition, the definition of "early-onset" breast cancer ranged from 30 to 45 years, depending on the insurance carrier. Most policies addressed $B R C A$ testing for a man affected with breast cancer; however, these policies were also inconsistent between insurance companies. One company required that patients consider primary prevention (i.e., prophylactic mastectomy, or oophorectomy) for $B R C A$ testing to be covered.

\section{DISCUSSION}

There are few published studies that characterize health insurance coverage of genetic services in the United States. Our results support and document what many genetic service providers have long suspected: there is wide variability in coverage criteria across third-party payers and these criteria are not always consistent with current professional recommendations. Our results also suggest strategies to improve coverage of and reimbursement for genetic services in the United States.

Based on the combined results of the questionnaire and policy review, insurance companies seem to take one of two views toward coverage of genetic services. Some companies (e.g., Companies B and C) seem to view all genetic services as medically necessary, covering most genetic services (with occasional limitations noted in specific policies). Other companies (e.g., Company A) seem to view genetic services as medically necessary only when they will directly impact a patient's medical management (i.e., prophylactic mastectomy after positive $B R C A$ result). All other genetic services are not covered, including preconception genetic services and any genetic testing for diseases that cannot be treated. Not surprisingly, the more inclusive view of the utility of genetic services was associated with better coverage of these services. We are unclear whether this represents a broader company-wide attitude toward health care or an attitude specific to genetic testing. Some companies' focus on the impact of testing on a patient's medical management implies an interest in evidence-based medicine; these results support the need to continue publishing evidence-based outcomes data for genetic counseling and genetic testing.

In addition to insurers' disparate attitudes toward genetic services, selection of published policy topics seemed somewhat arbitrary: more than one third of these topics (38\%) were found in policies from only one or two health insurance companies. No companies provided information on their public websites about how topics were selected, and there was no obvious pattern such as incidence of disease, availability of treatment, or presence of clinical diagnostic criteria to explain the selection of policy topics. For example, one company has a policy regarding genetic testing for cerebral autosomal dominant arteriopathy with subcortical infarcts and leucoencephalopathy, whereas no company has a policy regarding genetic testing for autosomal dominant polycystic kidney disease. This arbitrariness is reminiscent of the extensive variability in state newborn screening programs before expanded newborn screening gained popularity: parents and family advocacy groups lobbied for inclusion of very rare disorders, and lawmakers often chose disorders for inclusion on the basis of political motivations without critical scientific analysis. ${ }^{14}$

Although many topics were addressed by a single insurance company, only a handful were reviewed by nearly all third-party payers in Illinois with published policies. Alzheimer disease testing and $B R C A$ testing were among the most frequent policy topics in our study. Several factors could contribute to the relative popularity of these topics, including physician familiarity with these diseases. Greendale and Pyeritz ${ }^{15}$ suggest that physicians' familiarity with genetic conditions may be more strongly influenced by the lay press than by peer-reviewed journal articles, which implies that medical directors of insurance companies may also be more likely to propose policies regarding genetic diseases that are particularly well known.

Another factor contributing to the large number of policies regarding $B R C A$ testing could be the release of the US Preventive Services Task Force ${ }^{16}$ recommendations in 2005. This report incorporates guidelines from several professional societ- 
ies, including the American Society of Clinical Oncology, ${ }^{17}$ the National Comprehensive Cancer Network, ${ }^{18}$ and the American College of Medical Genetics. ${ }^{19}$ As many of the $B R C A$ policies in our study referenced some or all these recommendations, it may be that the publication of these guidelines encouraged third-party payers to consider policies addressing genetic testing for inherited breast and ovarian cancer. Third-party payers may also take note of each other's policies in an effort to stay abreast of new medical technologies.

One additional contributor to the frequency of $B R C A$ testing policies in our study could be the large direct-to-consumer marketing campaign in 2002 and 2003 from Myriad Genetic Laboratories, Inc. ${ }^{20}$ the laboratory that holds the patent for this test. This advertising campaign increased referrals for cancer genetic counseling services by $244 \%$ at one center and raised awareness of genetic testing for $B R C A$ mutations among physicians practicing outside of primary care. ${ }^{21}$ The marketing campaign also seemed to increase the number of $B R C A$ tests ordered by family practice physicians, internal medicine specialists, obstetricians and gynecologists, and oncologists. ${ }^{22}$ Four of eight policies in our study regarding coverage of $B R C A$ testing were first published after this marketing campaign, and all BRCA policies have been revised since 2003. In addition, there has been extensive media coverage of the Myriad patent debate. ${ }^{23}$ Although increased awareness of genetic services through media attention has benefits, these results again suggest that genetic service providers should be more involved in the selection and review of genetic service policies and should provide policy makers with appropriate peer-reviewed literature.

Coverage criteria were most consistent around topics for which consensus criteria or professional recommendations have been written. Policies regarding $\mathrm{CF}$ carrier screening and first trimester screening for fetal aneuploidy are generally consistent with recent committee opinions from the American College of Obstetrics and Gynecology. ${ }^{24,25}$ Criteria for coverage of colon cancer-related genetic testing were also very consistent, and all companies in Illinois with policies referenced the Amsterdam criteria ${ }^{11}$ and Bethesda guidelines ${ }^{12}$ by name. In contrast to the consistency of policy positions regarding testing for hereditary colon cancer, third-party payers varied widely on criteria for coverage of $B R C A$ testing. One factor associated with this variability may be the lack of consensus among professional organizations: the National Comprehensive Cancer Network, ${ }^{18}$ American College of Medical Genetics, ${ }^{19}$ American Society of Clinical Oncology, ${ }^{17}$ and National Society of Genetic Counselors ${ }^{26}$ have all issued different guidelines for $B R C A$ testing. Although most health insurance companies in Illinois adapted their policies from one or several of these recommendation statements, several companies did not incorporate professional guidelines into their coverage criteria at all. These results strongly suggest that a single comprehensive consensus statement for $B R C A$ testing could improve insurance coverage and help make coverage criteria more consistent across insurance carriers.

In addition to the inconsistencies noted across insurers, several companies had policies that reflected inaccurate information. For example, the policy of one company regarding genetic testing for FAP syndrome inaccurately stated that this test is considered medically necessary to rule out the diagnosis of Klinefelter syndrome. Klinefelter syndrome is not known to be associated with the $A P C$ gene, FAP syndrome, or an increased risk of colon cancer. ${ }^{27}$ Additionally, another insurer's criteria for coverage of $B R C A$ testing did not adequately address paternal family history or ovarian cancer risks associated with mutations in these genes. There was also an inconsistency noted between the answers from the survey arm of the study and the published policies from the same company. The medical director of Company A said that carrier screening for CF would not be covered preconceptionally (Table 1), but published policy of Company A regarding this service was consistent with the American College of Obstetrics \& Gynecology recommendation that all couples planning a pregnancy be offered CF screening. These inaccuracies and inconsistencies are troubling and again point to the importance of genetics professionals' involvement in the creation of policies regarding coverage of genetic services.

Several health insurance companies in Illinois had policies addressing general genetic counseling services. The companies that covered genetic counseling services uniformly tied these services to genetic testing. Although genetic counseling is a critical component of the genetic testing process, it is also an important service to help patients obtain risk assessment and information regarding the potential appropriateness of genetic tests and to determine whether undergoing a test is in the patient's best interest. According to several policies in our study, genetic counseling would not be covered if the patient elected not to proceed with genetic testing. Again, more outcome data on the benefits of the service of genetic counseling could help persuade insurance companies to cover genetic counseling independently of genetic testing.

Although several insurance companies in our study had policies regarding genetic counseling, only two of these policies specifically reference genetic counselors as appropriate providers of this service. The lack of explicit recognition of genetic counselors does not necessarily imply that their services are not covered. Alternatively, this may reflect an opinion that genetic counseling can be provided by many types of health care providers or may suggest a general lack of awareness of genetic counselors as allied health professionals. ${ }^{4,5}$ The coverage of genetic counseling services performed by nonspecialists is problematic, because studies have consistently shown that physicians without special training in genetics order inappropriate tests, do not provide informed consent for testing, and misinterpret genetic test results. ${ }^{28-30}$ Because they understand the limitations of genetic testing, genetic counselors play a large role in helping to minimize the unnecessary use of genetic tests. ${ }^{3}$

Coverage of and reimbursement for genetic counseling services remains a challenge to the genetic counseling profession. Genetic counselors are not yet recognized as providers under the Social Security Act ${ }^{9}$ and thus cannot bill Medicare for their services. Many third-party payers follow the Center for Medicare and Medicaid Services' recognition of health care providers when determining who is eligible to bill for services, but there is no requirement that private insurers do so. ${ }^{1}$ Our results confirmed that at the time of this study, conducted just as licensure of genetic counselors was taking effect in Illinois, most health insurance companies in Illinois did not credential genetic counselors. There are no published data documenting whether state licensure improves the ability of genetic counselors to be reimbursed for their services. However, the suggestions made by the medical director of Company A, including lobbying Congress and the Illinois General Assembly to mandate coverage of services provided by genetic counselors validate professional organizations' work to improve reimbursement by appealing to state and federal legislatures.

This study has several limitations. First, we were unsuccessful in obtaining information from publicly funded health care options such as Medicaid and Medicare. Second, the completion rate for the survey arm of the study was low (30\%); however, this rate is comparable with response rates in other health coverage policy surveys. ${ }^{6}$ The low response rate may have resulted in a 
biased sample, because medical directors with more familiarity with genetic services may have been more likely to respond. An additional limitation is the fact that the depth of data collected varied between response methods (in-person interview for Company A versus mailed surveys for Companies B and C). The medical directors from Companies $\mathrm{B}$ and $\mathrm{C}$ did not complete the entire survey. As noted earlier, the medical director of Company A provided information that was inconsistent with published policies of Company A regarding genetic services; this may also have been true for the other participants. Despite these limitations in the survey arm of the study, our results from the policy analysis represent current genetic services coverage information for millions of insured residents in Illinois. Because $80 \%$ of the companies included in this study offer health insurance on a national or regional scale, this information may also be generalizable to residents of other states.

Third, our study was limited to a review of broad third-party payer policies toward genetic services. These policies may or may not correspond to coverage at the individual plan level. Each insurance company offers many different plan options, and employers or individual subscribers may choose from among these options. For example, an insurance company may have policies supporting coverage of genetic testing, but an individual plan from within that company may carry a general exclusion against all genetic testing. The data from individual plans are not publicly available, so it is currently impossible to assess coverage at this level.

Finally, the difficulty of the data collection in both arms of this study warrants mentioning. We spent nearly 2 months attempting to contact medical directors of the 10 largest insurance companies in Illinois. Five medical directors never returned repeated phone calls, emails, and mailed surveys, and two medical directors actively declined to participate. Interestingly, all three participants in the first arm of the study were successfully recruited through mailed surveys (despite several phone calls to the same directors before the mailings). In addition, the published policies were very difficult to find on company websites and were often buried inside provider manuals. These challenges are not unique to studies addressing genetic services: Boom et al. ${ }^{31}$ experienced similar obstacles in a survey regarding insurance coverage for adolescent vaccinations. This lack of readily accessible information regarding coverage of genetic services is frustrating to both patients and providers and reflects larger problems with transparency in managed care. The difficulty of data collection and small sample size may explain in part why there are so few published studies on coverage of genetic services.

\section{CONCLUSIONS}

Third-party payers have variable policies regarding coverage for genetic services in Illinois. Our study is one of only a few to characterize this variability and has implications both locally and nationally. These findings give insight into how third-party payers make coverage decisions and could ultimately impact health care consumers nationwide.

Our data point to several specific suggestions for further study and strategies for improvement of coverage and reimbursement for genetic services. Suggestions for future efforts include the following:

- Further studies should be conducted in other states to compare coverage of genetic services on a regional and national basis.
- States that have enacted genetic counselor licensure should assess whether this has impacted the policies of third-party payers in any measurable way.

- A comparison of health insurance companies' attitudes toward coverage of genetic services and coverage of nongenetic services could help establish whether policies and practices related to genetic services are unique or reflective of company-wide attitudes toward health care.

- Researchers should continue to publish evidence-based outcomes that address the value and cost-effectiveness of genetic services.

- Genetic service providers should continue to work toward legislative amendments that mandate coverage of services provided by genetic counselors.

- Professional societies should work together to create more consensus criteria for genetic testing, especially for $B R C A$ testing, and should alert third-party payers to consensus criteria as they become available.

- Genetic service providers should become more involved in the selection and development of coverage policies regarding genetic services. In addition, genetic service providers should engage with medical directors of third-party payers when claims are denied as a means of educating them about the utility of genetic services.

- Genetic service providers should work to educate human resource representatives and benefits negotiators at large employers about the value of genetic testing and counseling and encourage them to request increased coverage of medically necessary or clinically relevant genetic services.

\section{ACKNOWLEDGMENTS}

This work was supported by a grant from the Illinois Department of Public Health and by the Graduate Program in Genetic Counseling at Northwestern University.

\section{REFERENCES}

1. Secretary's Advisory Committee on Genetics, Health, and Society. Coverage and reimbursement of genetic tests and services. US Department of Health and Human Services, 2006. Available at: http://www4.od.nih.gov/oba/sacghs/ reports/CR_report.pdf.

2. Harrison TL, Doyle DL, McGowan C, et al. Billing for medical genetics and genetic counseling services: a national survey. J Genet Couns 2010;19:38-43.

3. Williams MS. Genetics and managed care: policy statement of the American College of Medical Genetics. Genet Med 2001;3:430-435.

4. Gibons A. Study results: employer-based coverage of genetic counseling services. Benefits Q 2004;20:48-68.

5. Billings PR, Carlson RJ, Carlson J, et al. Ready for genomic medicine? Perspectives of health care decision makers. Arch Intern Med 2005;165:1917-1919.

6. Kuerer HM, Hwang ES, Anthony JP, et al. Current national health insurance coverage policies for breast and ovarian cancer prophylactic surgery. Ann Surg Oncol 2000; 7:325-332.

7. Illinois Department of Public Health. Illinois state genetics plan. Springfield, IL: Office of Health Promotion, 2007. Available at: www.idph.state.il.us/ HealthWellness/Genetics_07StatePlan.pdf. Accessed June 1, 2010.

8. Illinois Department of Insurance. Market share report, 2006. Available at: http://www.idfpr.com/DOI/Reports/Report_Links.asp.

9. Social Security Act, 1965. Available at: http://www.ssa.gov/OP_Home/ssact/ ssact.htm.

10. Illinois Medical Practice Act of 1987. 225 ILCS 60. Available at: http:// www.ilga.gov/.

11. Vasen HF, Watson P, Mecklin JP, Lynch HT. New clinical criteria for hereditary nonpolyposis colorectal cancer (HNPCC, Lynch syndrome) proposed by the International Collaborative group on HNPCC. Gastroenterology 1999;116:1453-1456.

12. Umar A, Boland CR, Terdiman JP, et al. Revised Bethesda Guidelines for hereditary nonpolyposis colorectal cancer (Lynch syndrome) and microsatellite instability. J Natl Cancer Inst 2004;96:261-268.

13. Humana. Medical coverage policy: genetic testing/genetic counseling/ pharmacogenetic testing. Available at: http://apps.humana.com/tad/tad new $/$ returnContent.asp?mime $=$ application $/$ pdf $\&$ id $=5298 \&$ issue $=608 . \quad$ Accessed January 4, 2008. 
14. Watson MS. Current status of newborn screening: decision-making about the conditions to include in screening programs. Ment Retard Dev Disabil Res Rev 2006;12:230-235.

15. Greendale K, Pyeritz RE. Empowering primary care health professionals in medical genetics: how soon? How fast? How far? Am J Med Genet 2001; 106:223-232.

16. U.S. Preventive Services Task Force. Genetic risk assessment and BRCA mutation testing for breast and ovarian cancer susceptibility: recommendation statement. Ann Intern Med 2005;143:355-361.

17. American Society of Clinical Oncology. American Society of Clinical Oncology policy statement update: genetic testing for cancer susceptibility. J Clin Oncol 2003;21:2397-2406.

18. Daly MB, Axilbund JE, Bryant E, et al. Genetic/familial high-risk assessment: breast and ovarian. J Natl Compr Canc Netw 2006;4:156-176.

19. American College of Medical Genetics. Genetic susceptibility to breast and ovarian cancer: assessment, counseling and testing guidelines. New York: New York State Department of Health, American College of Medical Genetics Foundation, 1999. Available at: http://www.health.state.ny.us/nysdoh/cancer/obcancer/ contents.htm. Accessed June 1, 2010.

20. Myriad Genetic Laboratories, Inc. Myriad Genetics launches direct to consumer advertising for breast cancer test, 2002. Available at: http://www.myriad.com/ news/release/333030.

21. Mouchawar J, Hensely-Alford S, Lauion S, et al. Impact of direct-to-consumer advertising for hereditary breast cancer testing on genetic services at a managed care organization: a naturally-occurring experiment. Genet Med 2005; 7:191-197.

22. Centers for Disease Control and Prevention (CDC). Genetic testing for breast and ovarian cancer susceptibility: evaluating direct-to-consumer marketing-
Atlanta, Denver, Raleigh-Durham, and Seattle, 2003. MMWR Morb Mortal Wkly Rep 2004;53:603-606.

23. Caulfield T, Bubela T, Murdoch CJ. (2007). Myriad and the mass media: the covering of a gene patent controversy. Genet Med 2007;9:850-855.

24. Committee on Genetics, American College of Obstetricians and Gynecologists. ACOG Committee Opinion. Number 325, December 2005. Update on carrier screening for cystic fibrosis. Obstet Gynecol 2005;106:1465-1468.

25. ACOG Committee on Practice Bulletins. ACOG Practice Bulletin No. 77: screening for fetal chromosomal abnormalities. Obstet Gynecol 2007;109: 217-227.

26. Berliner JL, Fay AM. Risk assessment and genetic counseling for hereditary breast and ovarian cancer: recommendations of the National Society of Genetic Counselors. J Genet Couns 2007;16:241-260.

27. OMIM (Online Mendelian Inheritance in Man). 175100: Adenomatous polyposis of the colon. Baltimore: Johns Hopkins University, Center for Medical Genetics, 1996 Available at: http://www.ncbi.nlm.nih.gov/omim/175100. Accessed June 1, 2010.

28. Giardiello FM, Brensinger JD, Petersen GM, et al. The use and interpretation of commercial APC gene testing for familial adenomatous polyposis. $N$ Engl $J$ Med 1997;336:823-827.

29. Hayflick SJ, Eiff MP, Carpenter L, Steinberger J. Primary care physicians' utilization and perceptions of genetics services. Genet Med 1998;1:13-21.

30. Cohn GM, Gould M, Miller RC, Habecker-Green J, Macri CJ, Gimovsky ML. The importance of genetic counseling before amniocentesis. J Perinatol 1996; $16: 352-357$.

31. Boom JA, Nelson CS, Middleman AB, Frugé A, Kozinetz CA. Investigation of obstacles to accessing information regarding private medical insurance coverage and physician reimbursement for adolescent vaccination. $J$ Adolesc Health 2009;44:298-301. 